V Seminário Anual Científico e Tecnológico | Bio-Manguinhos

\title{
BIO 09 - Aplicação da citometria de fluxo no monitoramento de células CHO
}

Maíra Peixoto Pellegrini1 ${ }^{*}$; Marina Vergne de Almeida'; Tiago Pereira dos Santos ${ }^{1}$; Esther Vinhais Gutierrez ${ }^{1}$; Raquel Ferraz Nogueira²; Rodrigo Coelho Ventura Pinto².

1 Bio-Manguinhos / Fiocruz;

2 Beckman Coulter.

\section{Introdução:}

A produção de biofármacos em células animais depende intimamente das condições de cultivo e da fisiologia celular, onde o monitoramento de importantes parâmetros, como a concentração e viabilidade celular, torna-se crucial para garantir a qualidade da molécula. Processos produtivos normalmente utilizam a técnica de exclusão do corante vital azul de tripan para a quantificação da concentração celular e da viabilidade. Porém, algumas linhagens celulares empregadas em processos produtivos se caracterizam pelo crescimento em suspensão, mas formando agregados celulares. Este fenômeno pode dificultar a contagem, pois grumos de maior tamanho não conseguem acessar os quadrantes de contagem e as células mais internas em grumos menores não entram em contato com o corante e não são facilmente identificadas, resultando em potencial erro de quantificação. A contagem dos núcleos pela coloração com cristal violeta é uma alternativa, no entanto, a presença de células polinucleadas em linhagens como a $\mathrm{CHO}$ pode, também, interferir na avaliação.

\section{Objetivo:}

Avaliar a implementação do citômetro de fluxo CytoFlex no monitoramento do cultivo celular em um processo produtivo com células $\mathrm{CHO}$ recombinantes (CHO-EPOhr).

\section{Metodologia:}

Dois cultivos de células CHO-EPOhr foram propagados em biorreator do tipo wave e monitorados por diferentes metodologias de quantificação: coloração de células mortas pelo azul de tripan e análise por microscopia (padrão); coloração dos núcleos pelo corante cristal violeta e análise por microscopia; análise morfológica por citometria de fluxo com e sem desagregação celular; coloração de células mortas pelo iodeto de propídeo (PI) e análise por citometria; coloração de núcleos pelo PI e análise por citometria. 


\section{Resultado:}

As quantificações de células viáveis e totais pelo azul de tripan e cristal violeta apresentaram resultados discrepantes, alcançando diferença de 1,57X. A desagregação dos grumos é importante para a precisa quantificação por citometria, evitando também o entupimento do equipamento. As quantificações de células mortas por citometria, avaliando morfologia celular ou marcação pelo PI, apresentaram resultados semelhantes para viabilidade mas com pequenas diferenças na concentração celular. Isto indica que a análise de células mortas e viabilidade pode ser realizada sem PI, reduzindo uma etapa da metodologia. As quantificações por citometria, em geral, se assemelharam às quantificações pelo cristal violeta, exceto nos dois últimos dias da avaliação de células viáveis, e apresentaram variabilidade reduzida (DP <5\%). As contagens de núcleos por citometria resultaram em contagens abaixo do esperado, mas esta técnica é capaz de analisar ciclo celular, importante para caracterização de cultivos.

\section{Conclusão:}

O CytoFlex se mostrou uma excelente alternativa para o monitoramento de células durante um processo produtivo. Apesar da necessidade da etapa de desagregação celular, as leituras são rápidas, permitindo a realização de réplicas da mesma amostra e aumentado a confiabilidade do resultado. Além disso, o equipamento permite outras análises, como ciclo celular e apoptose, importantes para o monitoramento da fisiologia celular.

\section{Palavras-chave: Célula CHO; Citometria de Fluxo; Monitoramento}

